Faculty of Business

Faculty Publications

This is a post-print version of the following article:

Managing Traditions: A Critical Capability for Family Business Success, Family Business Review

Roy Suddaby \& Peter Jaskiewicz

2020

The final publication is available at:

https://doi.org/10.1177/0894486520942611

Citation for this paper:

Suddaby, R., \& Jaskiewicz, P. (2020). Managing Traditions: A Critical Capability for Family Business Success. Family Business Reivew, 33(3), pp. 234-

243https://doi.org/10.1177/0894486520942611 


\title{
Managing Traditions: A Critical Capability for Family Business Success
}

\author{
Roy Suddaby \\ Full Professor; Francis G. Winspear Chair \\ Peter B. Gustavson School of Business \\ University of Victoria \\ British Columbia, Canada \\ Email: rsuddaby@uvic.ca \\ Phone: 250-721-6401 \\ $\&$ \\ Carson School of Business \\ Washington State University \\ U.S.A \\ Peter Jaskiewicz \\ Full Professor; University Research Chair in Enduring Entrepreneurship \\ Telfer School of Management \\ University of Ottawa \\ Ontario, Canada \\ Email: peter.jas@uottawa.ca \\ Phone: 613-562-5800 (4730)
}

\section{Acknowledgements:}

We are deeply indebted to Alfredo de Massis, Josip Kotlar, Don Neubaum, and Tyge Payne for their outstanding feedback on an earlier draft of this editorial. 


\section{Introduction}

Our purpose in this editorial is to draw attention to the powerful but under-theorized role played by traditions in family businesses. Our core argument is that traditions are the foundational element of successful family businesses. As we elaborate in this essay, we believe that the family business success and longevity is directly correlated with the capacity to successfully manage the creation, maintenance and intergenerational transmission of traditions.

Because of their unique nature, family business tensions are often intergenerational in character and, thus, rest on the family business's capacity to integrate past, present and future. We examine two key family business tensions in this essay. The first is the tension between the need to maintain the business or innovate. De Massis and colleagues (2016) refer to this tension as the "innovation paradox" but, for reasons that will become obvious later, we refer to it as the Theseus paradox, a classic thought experiment from ancient Greek philosophy premised on the mythological hero best known for killing the Minotaur.

The second is the tension between the need to honor the founder's vision of the firm or adapt to the vision of the children. While this tension is commonly labelled as an issue of succession, we view the tension as broader and deeper than mere succession and term this tension the Oedipus paradox, a reference to another character of Greek myth who, in his efforts to save his city, unwittingly kills his father. While the two paradoxes derive from broader tensions of continuity versus change, they differ in that the first is premised on theories of path dependence and the second is premised on theories of imprinting. Traditions are the primary mechanism by which these tensions are navigated in family businesses. While research has acknowledged traditions as a distinguishing characteristic of family businesses (Lumpkin, Martin, \& Vaughn, 2008), the construct of traditions is only weakly theorized. In the absence of a strong theoretical 
frame, however, the empirical evidence of the role played by traditions in navigating these essential tensions of the family business remains unclear.

We initiate the process of theorizing traditions in this editorial. We begin by describing how the hybrid structure of traditions as both structure (what gets transmitted across generations) and agency (the process of transmission) creates the opportunity to view traditions as both essentialist constructs that endure through time, and as subjective constructs that are constantly being reinterpreted in an ever moving present. We then introduce the literature on rhetorical history which provides a framework that explains how the process of reinterpreting the past to manage the present actually occurs. Finally, we use this emergent theoretical framework to explain how traditions are used to resolve the Theseus paradox and the Oedipus paradox in family businesses.

\section{Traditions}

Traditions are a frequently invoked but rarely defined construct in management theory. Traditions are patterns of belief, customs and symbolic practices that are transmitted from generation to generation (Shils, 1981). Traditions emerged as a central concept in management research on organizational culture several decades ago (Schein, 1985) and have reappeared, more recently, in studies of organizational identity (Ravasi \& Schultz, 2006) and organizational institutionalism (Dacin \& Dacin, 2008). Traditions have also emerged as a construct of interest in research on family businesses (Lumpkin et al., 2008) where they have been used to describe the uniqueness of innovation (or the lack thereof) in family businesses (De Massis, Di Minin, \& Frattini, 2015; De

Massis et al., 2016), how firms manage their brand identity (Lee \& Shin, 2015), and to explain how family businesses build socioemotional wealth (Brinkerink \& Bammens, 2018).

This growing body of research has reinforced our awareness of the foundational role that traditions play in family business identity and decision making. However, the role of human 
agency in creating, maintaining and changing traditions in family businesses is, largely, unexplored. In particular, when conceptualizing traditions, family business theorists lean heavily on two macro-social concepts - imprinting (Stinchcombe, 1965) and path dependence (Schreyögg \& Sydow, 2011) - each of which implicitly dampens human agency. As a result, family business research tends to invoke traditions to explain why family businesses are burdened by their history and thus are slow to change, risk averse (Lumpkin, Brigham, \& Moss, 2010), and innovate only within limited degrees of freedom (Ergodan, Rondi, \& De Massis, 2020). Collectively, these studies reinforce the 'iron cage' assumptions of neo-institutionalism in which human agency gets trapped in social restraints of our own making (DiMaggio \& Powell, 1983). Traditions, in this view, are understood as social structures that possess agency independent of, and superior to, their creators.

We must not forget, however, that traditions are beliefs, customs and practices that are consciously transmitted (Dacin, Dacin, \& Kent, 2019) by human actors who expend considerable effort to maintain them (Lawrence \& Suddaby, 2006). We must also not forget that many seemingly long-standing traditions are often of relatively recent invention, devised strategically by self-interested actors (Hobsbawm \& Ranger, 2012). Perhaps the most serious theoretical mischaracterization of traditions in the management literature in general and the family business literature in particular, however, is the assumption that traditions reflect the agency of past generations at the expense of current and future generations.

Traditions are hybrid structures composed not only of what gets transmitted from generation to generation (the traditium), but also how (the tradere) such intergenerational transmission occurs (Shils, 1981). The traditium and the tradere reflect objective and subjective elements of tradition. Even though they are forged in the past, and over time assume the appearance 
of objectivity, traditions are interpreted and reinterpreted by successive generations in an evermoving present. It is this act of ongoing reinterpretation of past traditions in the present to guide the future that gives agency to current generations and reverses the assumption that traditions only exert influence from the past to the present. By reinterpreting old traditions in new ways, the current generation(s) can express their agency and legitimacy in the present, by adapting rather than adopting the voice of the past.

Viewed as a construct with both objective and subjective dimensions, traditions become more ambiguous and flexible concepts that can be understood more as a resource for managers rather than an impediment to managerial action (Suddaby \& Foster, 2017). More critically, while most empirical studies on traditions have focused on what gets transmitted, few studies have engaged with how intergenerational transmission occurs. We do so here, by drawing on emergent theorizing on rhetorical history (Suddaby, Foster, \& Quinn-Trank, 2010) which suggests both a much more fluid and bidirectional interaction between past, present and future in which the processes of interpreting the past, in the present, for the future makes traditions more subjective and malleable than current theorization permits. And by placing the creation, curation and alteration of traditions in the realm of interpretive agency, we can better see how the interpretation of traditions might serve as a critical capability (Suddaby, Coraiola, Harvey, \& Foster, 2020) that mediates how family businesses deal with their essential tensions.

\section{Rhetorical History}

The ability to manage history is an emergent concept in management theory, but has been a longstanding practice of the nation-state. Enduring institutions like government (Anderson, 2006), the Catholic church (Kosseleck, 2004) and the monarchy (Hobsbawm \& Ranger, 2012) persist, in large part, because of their ability to create historical narratives that mask change as continuity and 
identity. Non-family firms have begun to recognize the value in managing the interpretation of the past, and a number of consulting firms have emerged to articulate how firms can use their history for competitive advantage (Lasewicz, 2015).

The capacity to manage interpretations of the past strategically has been termed rhetorical history, defined as "the strategic use of the past as a persuasive strategy to manage key stakeholders of the firm" (Suddaby, Foster, \& Quinn-Trank, 2010: 157). The skill in deploying rhetorical history rests, in large part, on the adoption of a reflexive understanding of history, a historical consciousness (Suddaby, 2016), in which the interpretation of the objective facts of history can vary. Managerial agency arises in the interpretation of the past through a variety of techniques, including bracketing the continuous flow of historical events into meaningful periods (Kaplan \& Orlikowski, 2013), memorializing some facts as more significant than they actually are in an effort to create legitimacy (Foster, Suddaby, Minkus, \& Wiebe, 2011), or by strategically erasing some facts from collective memory in an effort to maintain a consistent organizational identity in times of turbulent change (Molnar \& Anteby, 2012).

Family businesses have engaged in practices of rhetorical history far longer than nonfamily firms, although empirical evidence suggests family businesses' use of rhetorical history is more intuitive and tacit than the formal and strategic use in non-family firms. For example, multigenerational family wineries rhetorically reconstruct past entrepreneurial achievements to maintain a continuous identity of entrepreneurship that can be imprinted across generations (Jaskiewicz, Combs, \& Rau; 2015). This is a clear application of memorialization techniques of rhetorical history. Another study shows how family businesses apply strategic forgetting in order to construct a narrative of an enduring identity as a fine wine maker while suppressing memories of less successful forays into the production of hard alcohol (Hills, Voronov, \& Hinings, 2013). 
While these initial efforts to apply rhetorical history to family businesses offer useful and creative steps in the right direction, they largely rely on essentializing assumptions of path dependence and imprinting. As noted above, these assumptions continue to privilege the past by granting too much agency to history and too little agency to the actors who narrate, curate and interpret it. As a result, existing studies continue to see traditions as a restraint on managerial agency, rather than as an interpretive resource that can be used to promote change and adaptation while still honoring the past. One exception is Sinha, Jaskiewicz, Gibbs and Combs (2019). Beyond observing rhetorical strategies of periodization or bracketing in a family business that strategically restructured its family history narratives to draw attention to some events in the family history and distract attention from others, the authors observed that the family business modified historical narratives beyond their original meaning - a process referred to as modifying guideposts. Taking our cue from this and other studies suggesting that organizations can reinterpret the past in the present, we explore how traditions might be used to manage two fundamental tensions in the family business, continuity vs. change and founder vs. inheritor, in the balance of this editorial.

\section{The Theseus Paradox: Managing the Tension between Continuity and Change}

Family businesses struggle with the tension between the need to maintain a continuous and coherent identity and the need to adapt to the changing demands of the present or the future. While all firms struggle with this tension, it is felt more acutely in family businesses because of the overarching need to honor the values, beliefs and vision of the founder (family). As a result, family businesses tend to privilege continuity over change - in spite of their (dormant) ability to follow through on innovation projects - a phenomenon referred to as the "innovation paradox" (De Massis et al., 2016). Until recently, most research suggested that family businesses tend to be less innovative than non-family firms (Gómez-Mejía et al., 2011), not because of their lack of capacity 
to change, but because of the deference to tradition and the need to maintain a consistent identity (Chrisman et al., 2015). More recent research, however, suggests that family businesses can be quite innovative, but are constrained in how innovation might be expressed by their deference to tradition (De Massis et al., 2016; Erdogan et al., 2020). To add to the conflicting results, a recent meta-analysis concludes that family businesses have little constraint on innovation output but, relative to their non-family peers, simply invest less in innovation in the first place (Duran, Kammerlander, Essen, \& Zellweger, 2016).

How do we make theoretical sense of these conflicting results? Are family businesses inertial or innovative? The answer lies in abandoning the essentialist assumptions of traditions as a constraint on change. An essentialist view focuses on the reified elements of traditions, the physical artefacts, aphorisms and rituals, that move from generation to generation. This is the traditium, of tradition. A rhetorical history lens, by contrast, focuses on the tradere, or the construction of meaning that occurs by the process or act of transmission across generations. If we focus on the physical or reified elements of tradition, the traditium, institutional structures appear much more enduring and resistant to change than they actually are. If, however, we focus on the processual or interpretive elements of tradition, the tradere, institutional structures appear to be more plastic or fluid, more amenable to change, than they actually are. In combination, thus, traditions, when skillfully applied, offer the amazing ability to mask continuity as change and change as stability.

The nuanced interplay of change and continuity between structure and meaning is perhaps best illustrated by Plutarch's description of the paradox of Theseus:

"The ship on which Theseus sailed with the youths and returned in safety, the thirty-oared galley, was preserved by the Athenians down to the time of Demetrius Phalereus. They took away the old timbers from time to time, and put new and sound ones in their places, so that the vessel became a standing illustration for the philosophers in the mooted question 
of growth, some declaring that it remained the same, others that it was not the same vessel." (Plutarch, Perrin, 1914, V1, 49).

The adage demonstrates how the physical elements (the traditium) of a symbolic entity can become decoupled from its meaning (tradere). In the case of Theseus, the meaning, identity and authenticity of the entity persists long after the structure has changed. But traditions can also manage the tension between continuity and change in an opposite process; the structural elements of tradition - the rites, the stories, the monuments - remain intact across generations, but their meaning is often adapted and updated to maintain relevance with contemporary circumstances.

The interpretive revision of traditions is accomplished through the application of the techniques of rhetorical history that focus on the subjective-interpretive processes by which traditions are passed from generation to generation. Family values are often communicated through traditional aphorisms, adages and mottos designed to pass the wisdom of the founders to successive generations. These adages, however, can be skillfully constructed within a rhetoric of analogical ambiguity, which encourages successive generations to interpret the adage through analogy rather than literally. Analogies focus attention on accepted similarities between two entities to support the argument that some further similarity or continuity exists between those entities (Bartha, 2019).

Analogical reasoning is most typically used in historical or legal analyses because it permits a creative abstraction of generic principles that allow a static document drafted generations ago to be reinterpreted in the context of present circumstances. Analogical reasoning, thus, allows legal scholars to interpret the U.S. Constitution, a document written two and half centuries ago, and apply its meaning to issues that arise today or might arise in the future (Sunstein, 1993). Analogical reasoning also allows ancient Confucian proverbs (Huang, 2007) or parables from the Old and New Testament (Tracey, 1981), to retain their relevance and poignancy today (Lieber, 1984). 
Traditions exemplify analogical reasoning. They function, not in opposition to change, but rather, through their hybrid construction of traditium and tradere. The hybrid structure of traditions makes them a useful device to actively mediate change by making radical, discontinuous change seem incremental, evolutionary and consistent with the past. Moreover, the hybrid structure of traditions provides an answer to the core question as to whether family businesses are inherently innovative or inertial by offering an important distinction between how family businesses innovate in practice, and how they talk about their innovation, both internally and externally. While family businesses may, based on their R\&D investments, innovate as much or more than their corporate counterparts, as Duran and colleagues (2016) profess, family businesses talk and think about their innovative practices in a very different way than do non-family firms. Rather than trumpeting a new product, practice or process as a radical departure from the past (i.e., a disruptive innovation), the ethos of family businesses is to legitimate such agency as a form of continuity with the past, as an incremental extension of the enduring legacy of the founder (family) (Jaskiewicz et al., 2015). Rhetorical history, thus, focuses attention on how the innovation is explained across generations, dampens the degree of change and allows the firm to mask change as continuity (Suddaby \& Foster, 2017). Rhetorical history resolves the Theseus paradox by using the tradere of tradition to focus attention on the structural continuity of Theseus' ship rather than its new component parts.

\section{The Oedipus Paradox: Managing the Tension between Generations}

Family businesses also struggle with issues of succession. Most family businesses rarely survive beyond the first generation (Le Breton-Miller, Miller, \& Steier, 2004) making succession one of the most important and yet one of the most theoretically fragmented issues in family business. Drawing on theories from organizational behavior (Daspit, Holt, Chrisman, \& Long, 2016) and family science (Jaskiewicz, Combs, Shanine, \& Kacmar, 2017), a growing stream of research 
emphasizes that broadening and deepening intergenerational communication and interaction helps to mitigate the succession problem in family businesses.

While a useful step in the right direction, existing studies appear to implicitly assume a largely unidirectional flow in the exchange process from the incumbent generation to the heritor generation. While the model is designed to encourage mutual exchange of information between generations, the inherent dominant position that the incumbent holds in any family business signals a serious power asymmetry as an inherent element of any family exchange. This is reflected in the emphasis placed on the role of "selecting" (Sharma, Chrisman, \& Chua, 2003) and training the "next gen" (Barbera, Bernhard, Nacht, \& McCann, 2015) and choosing the formal or contractual context within which these negotiations may occur (Royer, Boyd, Simons, \& Rafferty, 2008). Despite the best efforts to maintain a bi-directional exchange in the family business, the flow of information and power still seems to be assumed to move unidirectionaly, from the incumbent to the next generation (Garcia et al., 2019; Huang et al., 2019).

Much of the literature on family succession draws implicitly from theoretical assumptions of path dependence in which decisions made in the past delimit the options available for decisions to be made in the present or the future. Agency, in path dependence, is held by decision makers in the past, just as agency, in theories of family business, are assumed to be held by the founder or later generation senior leader. The absence of agency in a family has well known tragic consequences as depicted by the Greek playwright Sophocoles in his tragic account of Oedipus, the king of Thebes who unwittingly kills his father, marries his mother, thus bringing disaster to his kingdom and his family. The tragedy is used as the psychoanalytic foundation for the Oedipus complex in which a child develops feelings of desire for the opposite-sex parent and jealousy and 
anger for the same-sex parent. Both the play and the complex describe the tragedy that ensues when fate denies agency to youth or when decisions in the past deny agency in the future.

The Oedipus paradox in family businesses is that in order for the next generation to usefully exercise agency in the future, they must destroy the past in an act of Schumpeterian renewal. However, such acts of creative destruction in family businesses are often more destructive than creative, as evidenced by multiple studies which show that most family businesses fail "soon after the second generation takes control" (Miller, Steier, \& Le Breton-Miller, 2003: 513). The result is often tragedy, not only for the family business and its employees, but also for the general economy. In order for organizational behavior and family science theories to effectively resolve issues of succession, the unidirectional flow of time embedded in path dependence theory must be reversed and the heritor generation must be able to speak to, and exert influence, on the founder (family). But how do we reverse the flow of time? Traditions, particularly when viewed through the lens of rhetorical history, offer a resolution to this seemingly intractable problem. As we elaborate in the balance of this section, the interpretive aspect of traditions gives agency to the heritor generation by granting them the authority to reinterpret the intent, purpose and meaning of the founder (family)'s vision in the context of current and anticipated future environmental conditions. The capacity to manage the past by reinterpreting traditions is a capability of successful family businesses (Suddaby et al., 2020).

History is understood to be an objective constraint on the capacity of organizations to change. Path dependence is theorized as a limit to strategic choice in the same way that structural inertia is theorized as a limit to the capacity of organizations to adapt. Despite these constraints, we can identify a selection of firms that successfully adapt to change, just as we can identify a selection of managers who appear to cultivate strategic choice when most others do not. How do 
we explain this? The answer appears to rest in the differential ability to manage history (Suddaby et al., 2010). While most view history as an objective construct, with brute immutable facts that limit choice, a select view understand history as an interpretive concept in which the brute facts can be re-ordered, re-interpreted and understood in a way that makes history a resource rather than a constraint (Suddaby \& Foster, 2017). By narrating the traditions of the past in a way that makes them relevant and adaptable to contemporary conditions, one can mobilize stakeholder commitment to a shared past and identification with a common mnemonic project. In effect, emphasizing the interpretive element of tradition, gives agency to the heritor generation by allowing them to go back in time and speak with the voice of the founding family.

How does this occur? There are multiple techniques, but perhaps the approach most relevant to family businesses is through the rhetorical device of rhetorically reconstructing autobiographical memory. Autobiographical memory is a concept in social psychology that refers to the complex cognitive process by which individuals take episodic memories of their own experience and integrate them into a coherent narrative of the self (Fivush, 2011; Fivush, Habermas, Waters, \& Zaman, 2011). The capacity to narrate one's story of self to oneself in order to give an individual a coherent sense of self that is continuous and consistent in time is an incredibly complex act of individual agency. Curiously, a few rare individuals lose their cognitive ability to create an autobiographical memory (Tulving, 1985). Unsurprisingly, these individuals lose their sense of identity because identity is premised on the ability to construct a life narrative that conveys consistency in the past, present and future. Often, in order to achieve continuity of identity, individuals unconsciously shape their memories of the past, suppress other memories or re-order the sequence of memories in order to maintain a consistent life narrative. 
While the notion of autobiographical memory originates at the individual level of analysis, it has been theoretically applied to understand how organizations use rhetorical history to manage identity (Suddaby, Schultz, \& Israelsen, 2020). More usefully, the construct of autobiographical memory can be used to analyze how family businesses use traditions to enhance the bi-directional flow of information to more fully realize the potential of family socialization and communication practices. Our proposition is that the inheritor generation manifests agency by actively contributing to the ongoing revision of the autobiographical memory of the family business.

While there is little empirical research on how family businesses use rhetorical history to engage inheritors in the process of revising the firm's autobiographical memory (but see Jaskiewicz et al., 2015, and, Sasaki, Kotlar, Ravasi, \& Vaara, 2000 for notable exceptions), we can extrapolate from clinical applications of the technique in family counselling. Drawing from several decades of clinical experience, Fivush (2019) describes how valuable the process of collective reminiscing among family members is in enhancing autobiographical memory. Reminiscing is a form of rhetorical history in which family members relate stories of past experiences in a communal process of collective remembering. In family therapy techniques reminiscing is an established clinical practice used to foster intergenerational communication (Boszormenyi-Nagy \& Spark, 2014; Haight \& Webster, 1995).

More than just nostalgic recall of the past, reminiscing is a rigorous exercise of collective reflection that can reveal interpretations of the past unknown to other family members (Pratt, Norris, Hebblethwaite, \& Arnold, 2008). When used effectively, techniques of clinical reminiscence can give voice to all generations, not only in creating a common collective autobiography, but also in building a family's shared vision of the future (Pratt \& Fiese, 2004). Ultimately, family reminiscence therapy uses rhetorical history. It is "focused on language use in 
interaction, allowing an active and constructive medium that people use resourcefully to accomplish things" (Murakami \& Jacobs, 2017: 293).

While we tend to think of memory as an individual phenomenon, Halbwachs (1992) established that much of our memory is constructed in social institutions. Collective reminiscing is a process by which we share individual memories of episodes and integrate them into a coherent sense of collective identity. Such memories are not fixed in objective history, however. Instead they gain meaning and resonance only through ongoing acts of collective recall and revision that update the memory in order to correspond with current issues facing the collective and with aspirational visions of what the collective might become. Memory, in this view, is a process rather than a reified thing, and the value of the memory is not in its objective accuracy, but rather is in the process of continually introducing overlooked details or interpretations of the event in order to retain continuity with the past and relevance for the present and future.

In most families, reminiscing is an informal rhetorical process that encourages the social exchange of information, meaning and values bidirectionally across generations. Anecdotal evidence from some family business consulting firms suggests that, just as family counsellors encourage structured reminiscence to resolve family squabbles, so too do formal workshops in which multiple generations are brought together to work on structured projects (e.g., family histories, commemorative events, family museums) in which the family heritage is made open and available for collective reconstruction (Balmer, Blömbeck, \& Brunninge, 2013).

\section{Conclusion}

We have briefly sketched out how a deeper understanding of traditions can help family businesses navigate two of their most fundamental paradoxes: The Theseus paradox describes the difficulty family businesses experience in managing the pressure to innovate for the future, while 
maintaining allegiance to the values of the past. Most family businesses fail to navigate this paradox because they are trapped by the logic of path dependence which assumes that traditions established in the past restrict agency in the present. The family businesses that successfully navigate the Theseus paradox understand that traditions are hybrid concepts composed of structures and meanings. By skillfully applying techniques of rhetorical history, these family businesses are able to separate the structural act of innovation from how it is interpreted, as an act of continuity rather than disruption.

The Oedipus paradox describes the difficulty family businesses experience in managing intergenerational succession. Most family businesses fail to navigate this paradox because they are trapped by the logic of imprinting which assumes that founding values and traditions, once established, must be interpreted literally, in the context and time of the founder. We propose that the family businesses that successfully navigate the Oedipus paradox do so by applying techniques of rhetorical history designed to continually reinterpret the collective memory of the family business from the context of the next generation, rather than a literal interpretation from the context of the founder family.

Both paradoxes are resolved by viewing traditions as constructs with both fixed and malleable components. This hybrid nature of traditions as both structure, which is established in the past and endures, and meaning, which is continually updated in an ever-moving present, grants interpretive agency over the past by present and future generations. The relative neglect of the interpretive aspect of traditions, however, means that family business research has largely neglected the process by which traditions are communicated and managed intergenerationally.

We proposed that when familes lack the capacity to manage traditions, they are unable to address the inherent paradoxes of their businesses. In such cases, the weight of past and the burden 
of history holds a crippling grip on the family businesses' ability to adapt and change. Such family businesses rigidly enforce traditions and raise heritors to blindly conform to them. Under conditions of ambiguity, adhering to a literal understanding of traditions is typically the default option and such businesses succumb to deferring to the monument of the founder (family).

We point to rhetorical history as one important but overlooked mechanism by which firms can use traditions as a resource rather than a constraint on agency. Yet we know very little about the mechanisms by which traditions are used as a resource for adaptation and change in family business. Traditions are largely treated as a black box, undefined and relatively unexamined. We hope that this essay is a modest step forward in addressing this unfortunate status quo. Looking forward, we hope that the study of traditions, and how rhetorical history can be used for tradition management, will occupy a more central place in the family business research agenda. We similarly hope that researchers will pay attention not only to how the past restricts the present, but also to how the past can be leveraged to address problems in the present and the future. We believe that family businesses are a natural context to study the bi-directional relationship between past, present and future and how that capability might contribute to their ability to reinterpret traditions in an effort to reinvent themselves and, ultimately, succeed in dynamic market environments.

\section{References}

Anderson, B. (2006). Imagined communities: Reflections on the origin and spread of nationalism. Verso books.

Anteby, M., \& Molnar, V. (2012). Collective memory meets organizational identity: Remembering to forget in a firm's rhetorical history. Academy of Management Journal, 55(3), 515-540.

Balmer, J., Blombäck, A., \& Brunninge, O. (2013). The dual opening to brand heritage in family businesses. Corporate Communications: An International Journal, 18(3), 327-346.

Barbera, F., Bernhard, F., Nacht, J., \& McCann, G. (2015). The relevance of a whole-person learning approach to family business education: Concepts, evidence, and implications. Academy of Management Learning \& Education, 14(3), 322-346. 
Bartha, P. (2019). Analogy and Analogical Reasoning. In Edward N. Zalta (Ed.), The Stanford Encyclopedia of Philosophy. Spring.

https://plato.stanford.edu/archives/spr2019/entries/reasoning-analogy/

Boszormenyi-Nagy, I., \& Spark, G. M. (2014). Invisible loyalties: Reciprocity in

Intergenerational Family Therapy. Routledge.

Brinkerink, J., \& Bammens, Y. (2018). Family influence and R\&D spending in Dutch manufacturing SMEs: the role of identity and socioemotional decision considerations. Journal of Product Innovation Management, 35(4), 588-608.

Chrisman, J. J., Chua, J. H., De Massis, A., Frattini, F., \& Wright, M. (2015). The ability and willingness paradox in family firm innovation. Journal of Product Innovation Management, 32(3), 310-318.

Dacin, M. T., \& Dacin, P. A. (2008). Traditions as institutionalized practice: Implications for deinstitutionalization. In R. Greenwood, C. Oliver, K. Sahlin, K. \& R. Suddaby. The Sage Handbook of Organizational Institutionalism (pp. 327-352). Sage.

Dacin, M. T., Dacin, P. A., \& Kent, D. (2019). Tradition in organizations: A custodianship framework. Academy of Management Annals, 13(1), 342-373.

Daspit, J. J., Holt, D. T., Chrisman, J. J., \& Long, R. G. (2016). Examining family firm succession from a social exchange perspective: A multiphase, multistakeholder review. Family Business Review, 29(1), 44-64.

De Massis, A., Di Minin, A., \& Frattini, F. (2015). Family-driven innovation: Resolving the paradox in family firms. California Management Review, 58(1), 5-19.

De Massis, A., Frattini, F., Kotlar, J., Petruzzelli, A. M., \& Wright, M. (2016). Innovation through tradition: Lessons from innovative family businesses and directions for future research. Academy of Management Perspectives, 30(1), 93-116.

DiMaggio, P. J., \& Powell, W. W. (1983). The iron cage revisited: Institutional isomorphism and collective rationality in organizational fields. American Sociological Review, 48(2), 147-160.

Duran, P., Kammerlander, N., Van Essen, M., \& Zellweger, T. (2016). Doing more with less: Innovation input and output in family firms. Academy of Management Journal, 59(4), 12241264.

Erdogan, I., Rondi, E., \& De Massis, A. (2020). Managing the tradition and innovation paradox in family firms: A family imprinting perspective. Entrepreneurship Theory and Practice, 44(1), 20-54.

Fivush, R. (2011). The development of autobiographical memory. Annual Review of Psychology, $62,559-582$.

Fivush, R. (2019). Family narratives and the development of an autobiographical self: social and cultural perspectives on autobiographical memory. Routledge.

Fivush, R., Habermas, T., Waters, T. E., \& Zaman, W. (2011). The making of autobiographical memory: Intersections of culture, narratives and identity. International Journal of Psychology, 46(5), 321-345.

Foster, W. M., Suddaby, R., Minkus, A., \& Wiebe, E. (2011). History as social memory assets: The example of Tim Hortons. Management \& Organizational History, 6(1), 101-120.

Garcia, P. R. J. M., Sharma, P., De Massis, A., Wright, M., \& Scholes, L. (2019). Perceived Parental Behaviors and Next-Generation Engagement in Family Firms: A Social Cognitive Perspective. Entrepreneurship Theory and Practice, 43(2), 224-243. 
Gómez-Mejía, L. R., Cruz, C., Berrone, P., \& De Castro, J. (2011). The bind that ties:

Socioemotional wealth preservation in family firms. Academy of Management Annals, 5(1), 653-707.

Haight, B. K., \& Webster, J. D. (Eds.). (1995). The art and science of reminiscing: Theory, research, methods, and applications. Taylor \& Francis.

Halbwachs, M. (1992). On collective memory. University of Chicago Press.

Hills, S., Voronov, M., \& Hinings, C. B. (2013). Putting new wine in old bottles: Utilizing rhetorical history to overcome stigma associated with a previously dominant logic. Research in the Sociology of Organizations, 39(Part B), 99-137.

Hobsbawm, E., \& Ranger, T. (Eds.). (2012). The invention of tradition. Cambridge University Press.

Huang, C. C. (2007). The defining character of Chinese historical thinking. History and Theory, 46(2), 180-188.

Huang, X., Chen, L., Xu, E., Lu, F., \& Tam, K. C. (2019). Shadow of the Prince: Parentincumbents' Coercive Control over Child-successors in Family Organizations. Administrative Science Quarterly, 0001839219870449.

Jaskiewicz, P., Combs, J. G., \& Rau, S. B. (2015). Entrepreneurial legacy: Toward a theory of how some family firms nurture transgenerational entrepreneurship. Journal of Business Venturing, 30(1), 29-49.

Jaskiewicz, P., Combs, J. G., Shanine, K. K., \& Kacmar, K. M. (2017). Introducing the family: A review of family science with implications for management research. Academy of Management Annals, 11(1), 309-341.

Kaplan, S., \& Orlikowski, W. J. (2013). Temporal work in strategy making. Organization Science, 24(4), 965-995.

Koselleck, R. (2004). Futures past: on the semantics of historical time. New York: Columbia University Press.

Lasewicz, P. C. (2015). Forget the past? Or history matters? Selected academic perspectives on the strategic value of organizational pasts. The American Archivist, 78(1), 59-83.

Lawrence, T. B., \& Suddaby, R. (2006). Institutions and institutional work. In S. Clegg, C. Hardy, T. B. Lawrence (Eds), The Sage Handbook of Organization Studies (pp. 215-254). Sage.

Le Breton-Miller, I., Miller D., \& Steier L. (2003). Lost in time: Intergenerational succession, change, and failure in family business. Journal of Business Venturing, 18(4), 513-531.

Lee, Y. S., \& Shin, W. J. (2015). Marketing tradition-bound products through storytelling: A case study of a Japanese sake brewery. Service Business, 9(2), 281-295.

Lieber, M. D. (1984). Analogic ambiguity: A paradox of proverb usage. The Journal of American Folklore, 97(386), 423-441.

Lumpkin, G. T., Brigham, K. H., \& Moss, T. W. (2010). Long-term orientation: Implications for the entrepreneurial orientation and performance of family businesses. Entrepreneurship \& Regional Development, 22(3-4), 241-264.

Lumpkin, G. T., Martin, W., \& Vaughn, M. (2008). Family orientation: Individual-level influences on family firm outcomes. Family Business Review, 21(2), 127-138.

Miller, D., Steier, L., \& Le Breton-Miller, I. (2003). Lost in time: Intergenerational succession, change, and failure in family business. Journal of Business Venturing, 18(4), 513-531.

Murakami, K., \& Jacobs, R. L. (2017). Connecting dots: Family reminiscence. In Å. Mäkitalo, P. Linell, \& R. Säljö (Eds.), Advances in cultural psychology: Constructing human development: 
Memory practices and learning: Interactional, institutional and sociocultural perspectives (pp. 293-315). IAP Information Age Publishing.

Perrin, B. (1914). Theseus and Romulus. Lycurgus and Numa. Solon and Publicola. Loeb Classical Library 46. Lives, Vol. I.

Pratt, M. W., \& Fiese, B. H. (Eds.). (2004). Family stories and the life course: Across time and generations. Routledge.

Pratt, M. W., Norris, J. E., Hebblethwaite, S., \& Arnold, M. L. (2008). Intergenerational transmission of values: Family generativity and adolescents' narratives of parent and grandparent value teaching. Journal of Personality, 76(2), 171-198.

Ravasi, D., \& Schultz, M. (2006). Responding to organizational identity threats: Exploring the role of organizational culture. Academy of Management Journal, 49(3), 433-458.

Royer, S., Simons, R., Boyd, B., \& Rafferty, A. (2008). Promoting family: A contingency model of family business succession. Family Business Review, 21(1), 15-30.

Sasaki, I., Kotlar, J., Ravasi, D., \& Vaara, E. (2020). Dealing with revered past: Historical identity statements and strategic change in Japanese family firms. Strategic Management Journal, 41(3), 590-623.

Schein, E. H. (1985). Organizational culture and leadership. Jossey-Bass.

Schreyögg, G., \& Sydow, J. (2011). Organizational path dependence: A process view. Organization Studies, 32(3), 321-335.

Sharma, P., Chrisman, J. J., \& Chua, J. H. (2003). Succession planning as planned behavior: Some empirical results. Family Business Review, 16(1), 1-15.

Shils, E. (1981). Tradition. Chicago: University of Chicago Press.

Sinha, P. N., Jaskiewicz, P., Gibb, J., \& Combs, J. G. (2020). Managing history: How New Zealand's Gallagher Group used rhetorical narratives to reprioritize and modify imprinted strategic guideposts. Strategic Management Journal, 41(3), 557-589.

Stinchcombe, A. L. (1965). Social structure and organizations. Handbook of Organizations, 7, 142-193.

Suddaby, R. (2016). Toward a historical consciousness: Following the historic turn in management thought.M@n@gement,19(1),46-60.

Suddaby, R., Coraiola, D., Harvey, C., \& Foster, W. (2020). History and the micro-foundations of dynamic capabilities. Strategic Management Journal, 41(3), 530-556.

Suddaby, R., \& Foster, W. M. (2017). History and organizational change. Journal of Management, 43(1), 19-38.

Suddaby, R., Foster, W. M., \& Trank, C. Q. (2010). Rhetorical history as a source of competitive advantage. Advances in Strategic Management, 27, 147-173.

Suddaby, R., Schultz, M., \& Israelsen, T. (2020). Autobiographical Memory and Organizational Identity: The Role of Temporal Fluidity. In A. D. Brown (Ed.), Oxford Handbook of Identities in Organizations (pp. 375-390). Oxford University Press.

Sunstein, C. R. (1993). On analogical reasoning. Harvard Law Review, 106(3), 741-791.

Tracy, D. (1981). The analogical imagination: Christian theology and the culture of pluralism. Religious Studies Review, 7(4), 281-332.

Tulving, E. (1985). Memory and consciousness. Canadian Psychology/Psychologie Canadienne, 26(1), 1-12. 